\title{
The Geomorphologic Denudation of Oke-Igbo area of Ondo State, Southwest Nigeria: A Hydro-Climatic Influence.
}

\author{
${ }^{1}$ Ikubuwaje ,C, ${ }^{2}$ Obasi, R. A, and ${ }^{3}$ Jegede, G \\ ${ }^{1}$ Federal Polytechnic, Ado-Ekiti, PMB 5153, Ado-Ekiti \\ ${ }^{2}$ Dept of Geology, Ekiti State University, PMB 5363, Ado-Ekiti, Nigeria. \\ ${ }^{3}$ Federal University of Technology, Akure, Nigeria.
}

\begin{abstract}
The recent dynamic effect of hydro climatic influence on the geomorphology of the earth's crust calls for attention in order to properly manage the evolving ecological challenges and landscape dynamics. This study is carried out in built-up areas within basement complex terrain with the view of knowing the impact of rainfall, the major and one of the most widely studied meteorological variables in the tropics on the landforms. In the Nigerian context, the impact of climate change is felt majorly in terms of rainfall and temperature. Climatic data of rainfall for 37 years were collected and subjected to time series analysis using the SPSS Software and Micro Soft Excel. The trend analysis shows the correlation coefficient of 0.1 and variation rate of $0.7 \%$ implying that the rainfall varies in an upward trend. While the precipitation periodicity index is $255.67 \mathrm{~mm}$ for highest and $5.03 \mathrm{~mm}$ for lowest and the total annual rainfall is $1602 \mathrm{~mm}$, the percentage contribution of mean monthly rainfall for April- Oct is 1407.53 amounting to $87.84 \%$ an indication of high concentration of rainfall. The digital modeling show rugged hilly landscape of the terrain and other geomorphic features such as, river valleys, valleys, and drainage with slope gradients whose values vary from $8 \%-17 \%$ indicating a gentle to steep slope. The investigations and analyses reveal that the anthropogenic activities, topography of the study area coupled with the increased rainfall and intensity play the major roles in the denudation process of Oke-lgbo area of Ondo State.
\end{abstract}

Keywords: Correlation coefficient. denudation, rainfall trend, and Geomorphology

\section{Introduction}

The recent trend and increasing intensity of climatic influence on the surface of the earth in a challenging manner calls for a considerable attention. The geomorphological processes that evolved in the centuries past was probably a function of the emergence of plate tectonics. The emphasis now is on the detailed investigation of the processes that operate on landforms as well as the impact of climate on landform development (MyFundi, 2010). Rainfall is one of the most widely studied meteorological variables in the tropics when land denudations are considered. (Oguntoyinbo and Odingo,1979). Rainfall not only affects the ways and manner of human beings; but also it affects the facet of ecological systems, flora and fauna inclusive. Hence, the study of rainfall is important and cannot be over-emphasized (Obot and Onyeukwu, 2010). In the Nigerian context, the impact of climate change is felt majorly when there is an unusual rainfall and temperature.(Obasi and Ikubuwaje 2012)..Everywhere in the world where people change a natural ecosystem by agriculture and urbanization, the land degrades. The visible aspect of degradation is erosion. The processes that create landforms generally emerge from a combination of the materials (soils and rocks) and other contributory agencies such as geological dynamics, climate and human input. The land forms are affected by two key mechanisms of weathering and erosion. Much of the soil erosion /flood problems that occur on built-up environment results from construction activities of man and inappropriate land management that can effectively protect soil from the forces of water and wind. Jegede and Oguntuase (2000) report that erosion and flooding are threat to physical infrastructures, including residential accommodation, commercial and industrial property, roads, rail lines, bridges, and port installations. They also destroy farmlands, including standing crops. The impacts of rainfall and soil erosion can be long term and far reaching and the damage resulting from these phenomena is more costly in terms of remedial actions needed than the implementation of appropriate control measures. This study is carried out in built-up areas within the basement complex terrain with the view of knowing the impact of rainfall variables on the landforms. This is because rainfall is the major and one of the most widely studied meteorological variables in the tropics. It is imperative that past landforms, events and processes that formed them are studied in order to ascertain the reasons for the present degradation. Extrapolating this concept further, it is not difficult to see how geomorphologists can put this knowledge to good use by predicting how landforms will change in the future, and establishing which processes will produce which results. The resulting landform features, as well as the scars on the higher elevation, provide interesting case-studies for geomorphologists for the sake of understanding the fine physical thresholds that are crossed in such an event. 


\section{The Study Area}

Oke-Igbo area is located in Ile-Oluji/Oke-Igbo Local Government area of Ondo State in Southwest of Nigeria . The topography of the area is relatively high with elevation of about 800 meters above sea-level It lies between longitudes $4^{0} 42^{\prime} \mathrm{E}$ and $4^{0} 45^{\prime}$ and latitudes $7^{0} 8^{\prime} \mathrm{N}$ and $7^{0} 12^{\prime} \mathrm{N}$.

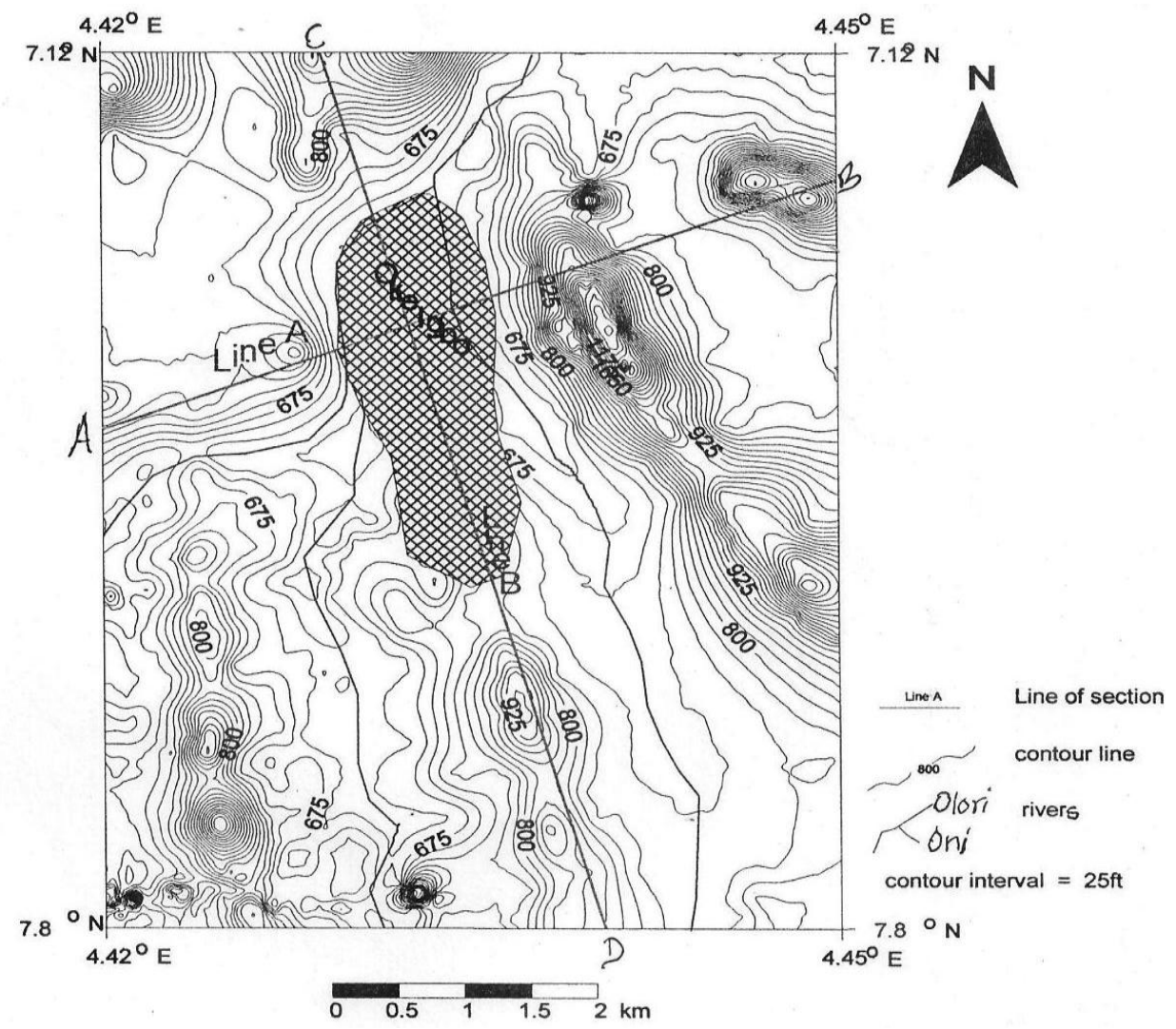

Fig 1: The topography of Oke-Igbo area of Ondo State.

The climate of Ondo State is of the lowland tropical rain forest type, with distinct wet and dry seasons . The mean annual total rainfall ranges between $1600 \mathrm{~mm}$ and $2000 \mathrm{~mm}$. Oke-Igbo is underlain by the basement complex terrain of the crystalline rocks of Nigeria (Rahaman and Malomo, 1983; Jegede 1999). The major rock is mainly the medium grained granite gneisses that are strongly foliated and commonly occurring as out crops. The surface of these outcrops are severely contorted with alternation of bands of dark and light coloured minerals. The light coloured band contains minerals that are essentially feldspar and quartz, while the dark coloured bands have abundant biotite and mica The soils derived from the basement complex rocks are mostly well drained with a medium texture. The field study investigations involve visual inspection of possible geological features and the soil texture.

Oke-Igbo has witnessed rapid territorial expansion mainly due to rapid-urban migration from neighboring settlements. The desire to own private property, has made private property developers to erect structures in different parts of the town and often without strict adherence to town planning regulations and management..

\section{Materials and Methods.}

The rainfall data of the study area for 37 years (1971-2007) were collected from the archives of the Nigerian Meteorological Agency, Lagos. The mean annual rainfalls are computed from the monthly rainfall data. Time series analysis is used to depict the temporal trend of mean rainfall using the SPSS and applying the model specifications from MOD_1 and model specifications from MOD_2 of the time Series . Sequence model is used to compute the mean annual rainfall that is used to produce the pareto chart of Ondo State for the years 1971-2007 ( Fig. 2a \& 2b) 


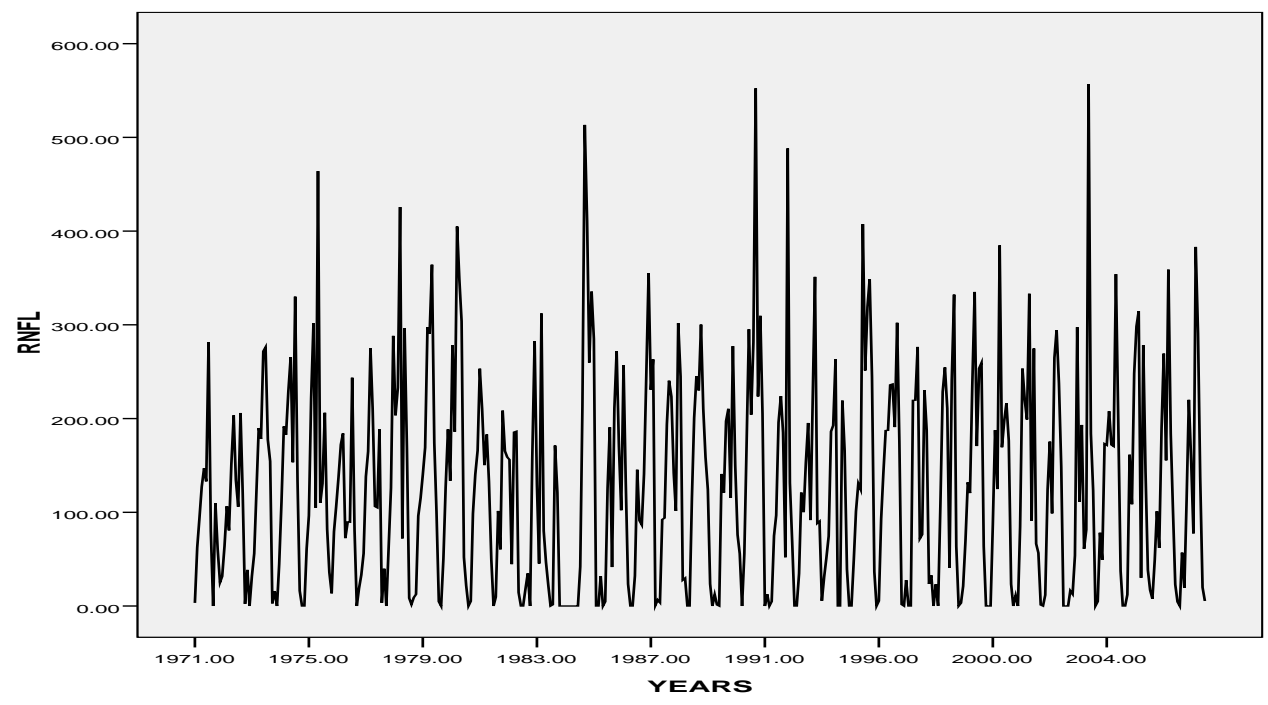

Fig.2a: Showing mean annual rainfall pareto chart of Ondo state for years 1971-2007

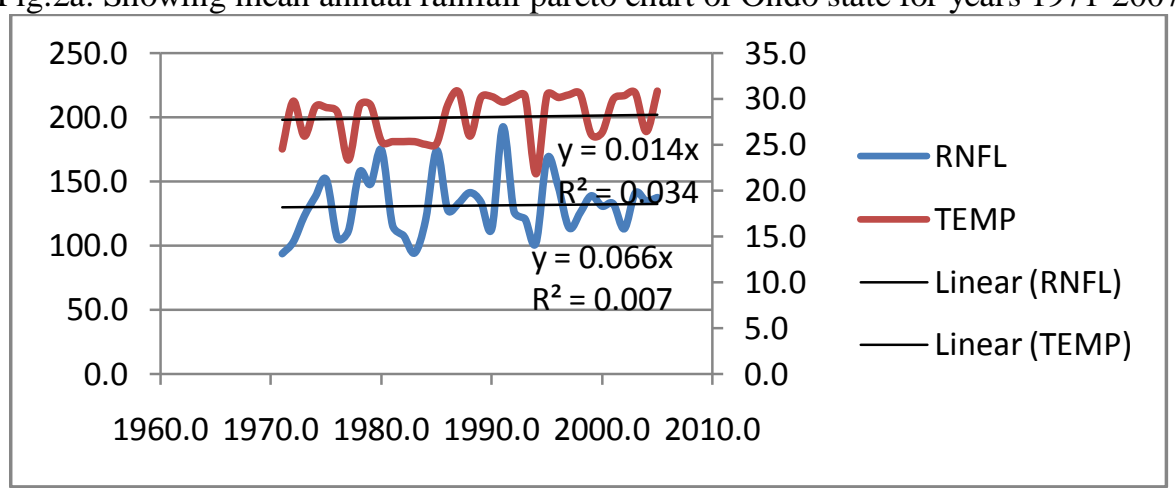

Fig 2b; Showing the Annual mean Rainfall and Temperature Trend for Ondo State years 1971-2005 (Obasi \& Ikubuwaje 2012)

The mean monthly rainfall for "n" years in each station was estimated by using the equation, which can be expressed in the form; $\check{\boldsymbol{R}}=\frac{1}{J} \sum_{j=1}^{n} R \boldsymbol{R}, \boldsymbol{J}$

Where $\mathrm{J}=$ number of years, $\mathrm{S}=$ Number of stations, $\mathrm{R}=$ Monthly rainfall value and $\check{\mathrm{R}}=$ Mean monthly rainfall. The percentage contribution to the annual rainfall for the months of April - October (rainy season), and November-March (dry season), were also determined (Table 1).

Table 1: Percentage Contribution of mean Monthly and Annual rainfall

\begin{tabular}{|l|l|l|l|l|}
\hline & RR (Nov-Mar) & RR (Apr-Oct) & Apr-Oct \% & Nov-Mar \% \\
\hline 1602.44 & 194.91 & 1407.53 & 87.84 & 12.16 \\
\hline 339.8 & & & & \\
\hline
\end{tabular}

This is based on findings by Adefolalu $(1985,1986 \mathrm{~b})$ using monthly rainfall data.

$\breve{\boldsymbol{R}}(\boldsymbol{w}) \boldsymbol{j}, \boldsymbol{s}=\left(\dot{\boldsymbol{R}} *(M A) j, s-\boldsymbol{R}_{(D) j, s}\right) * \mathbf{1 0 0}$

Where $\mathrm{w}=$ Rainy season; $\mathrm{D}=$ Dry season

Precipitation Periodicity Index (PPI) is the index used to determine the magnitude of rainfall variability (Hassan, 1996, 2008, Hassan and Adefolalu, 2003 )( Table 2) .

Table 2 :The Precipitation Periodicity Index study area

\begin{tabular}{|l|l|l|l|l|}
\hline Data & HIGHEST RR(A) & LOWEST RR(B) & Total Annual RR (Y) & PP (\%) \\
\hline Rainfall & $255.67 \mathrm{~mm}$ & $5.03 \mathrm{~mm}$ & $1602.44 \mathrm{~mm}$ & 15.61 \\
\hline
\end{tabular}

The PPI is expressed as percentage (\%). This index is computed using: $\mathbf{P P}=(\mathbf{A} / \mathbf{Y}-\mathbf{B} / \mathbf{Y}) * \mathbf{1 0 0} \%$ 
Where; $\mathrm{PP}=$ precipitation periodicity, $\mathrm{A}=$ the highest monthly rainfall, $\mathrm{B}=$ the lowest monthly rainfall, and $\mathrm{Y}=$ the total annual rainfall

Three co-ordinate data (x, y and $\mathrm{z}$ ) are determined from the topographical Map of Fig.1 and used to generate digital model and the slope profile of the study area (Figs.3).

Fig. 3: Topographic Profile along Oke-Igbo Section B- B’ North -South

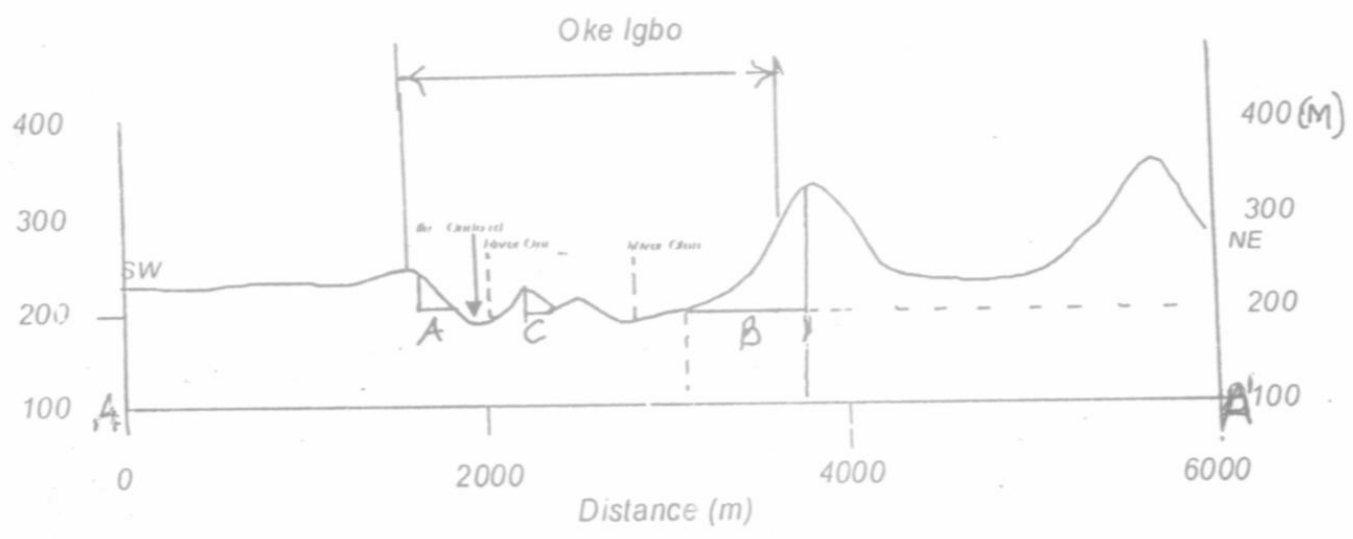

\section{Topographlic Profile across Oke - Igbo Section A-A' East-West}

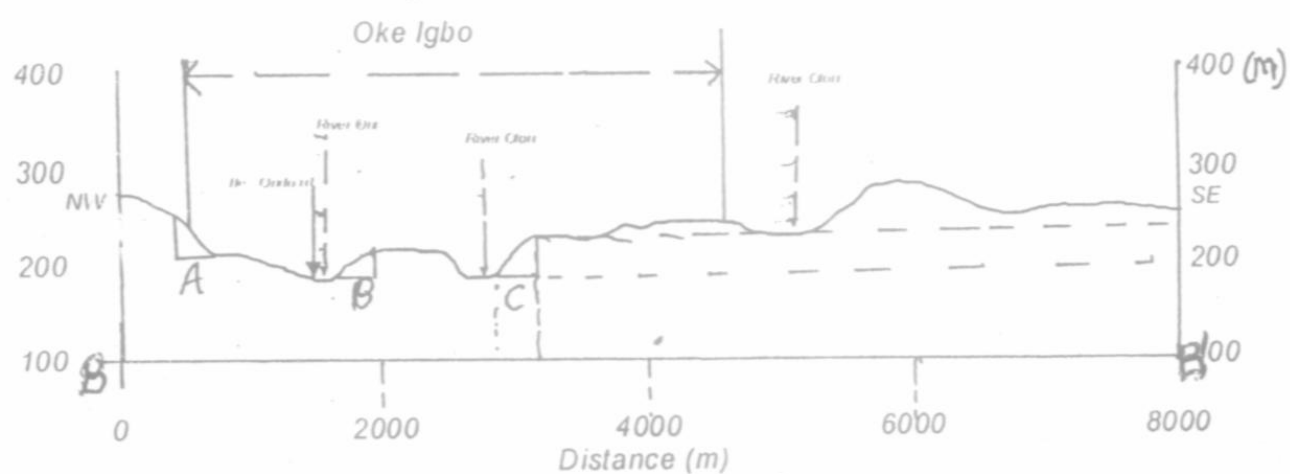

Slope profile is used to determine the slope gradient, nature and values. The results of the slope gradient values are presented in Table 3.

Table 3: Slope gradient across Oke-Igbo East-West and along Okr-Igbo profile North-South

\begin{tabular}{|l|l|l|l|l|l|l|}
\hline $\mathrm{XES}$ & A & B & C & A2 & B2 & C2 \\
\hline$y_{2}$ & 243.5 & 300.0 & 221.7 & 256.50 & 243.50 & 226.09 \\
\hline $\mathrm{y}_{1}$ & 200.01 & 200.0 & 200.0 & 213.04 & 200.00 & 200.00 \\
\hline$\Delta \mathrm{Y}$ & 43.5 & 100.0 & 21.7 & 43.46 & 43.50 & 26.09 \\
\hline $\mathrm{X}_{2}$ & 1883.7 & 3669.7 & 2395.4 & 687.50 & 3062.50 & 1875.00 \\
\hline $\mathrm{X}_{1}$ & 1627.9 & 3000.0 & 2225.6 & 375.00 & 2750.00 & 1562.50 \\
\hline
\end{tabular}


The Geomorphologic Denudation of Oke-Igbo area of Ondo State, Southwest Nigeria: A Hydro-

\begin{tabular}{|l|l|l|l|l|l|l|}
\hline$\Delta \mathrm{X}$ & 255.8 & 669.7 & 169.8 & 312,50 & 312.50 & 312.50 \\
\hline$\Delta \mathrm{Y} / \Delta \mathrm{X}$ & $43.5 / 255.8$ & $100.0 / 669.7$ & $21.7 / 169.8$ & $43.46 / 312.5$ & $43.5 / 312.5$ & $26.09 / 312.5$ \\
\hline$\%$ & 17 & 15 & 13 & 14 & 14 & 8 \\
\hline
\end{tabular}

Where $\mathrm{x}, \mathrm{y}$ and $\mathrm{z}$ axes of the gridlines are the elevation values of the contour lines. These data were imported into suffer software to produce the stereoscopic models of the study area.(Fig 4).

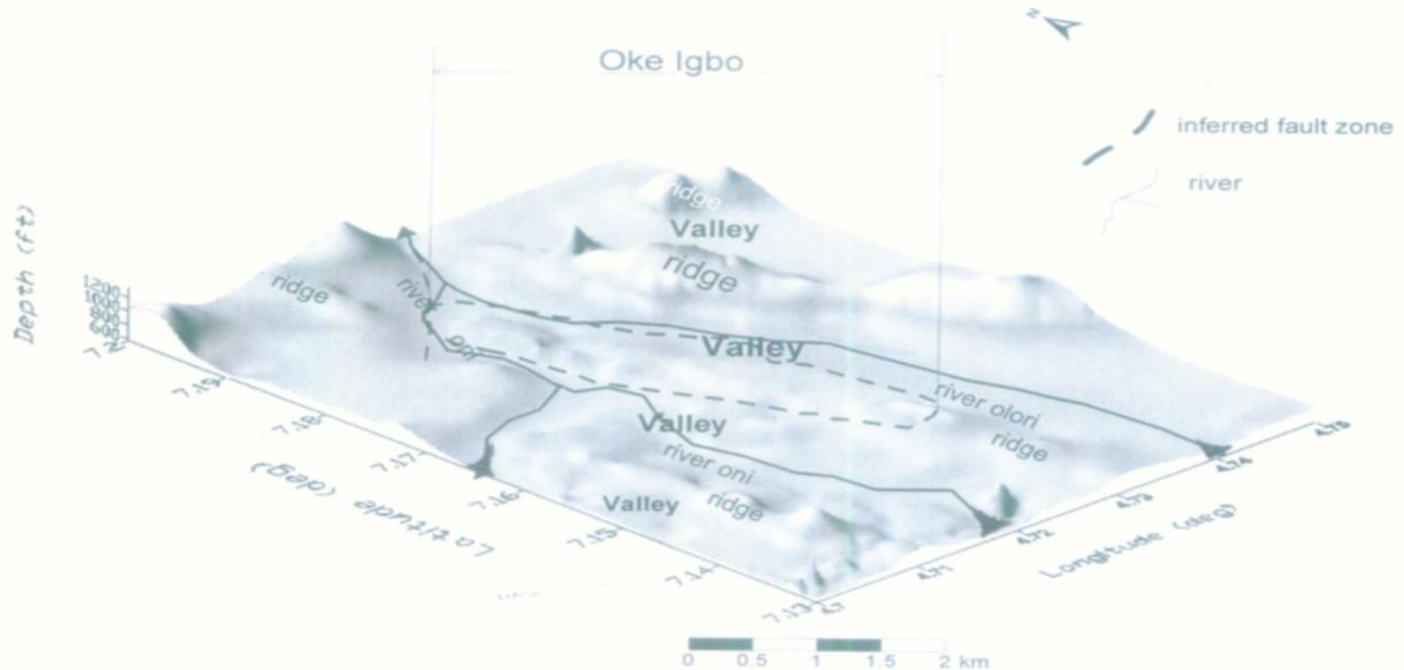

Fig 4. Stereoscopic Model of Oke-Igbo area of Ondo State

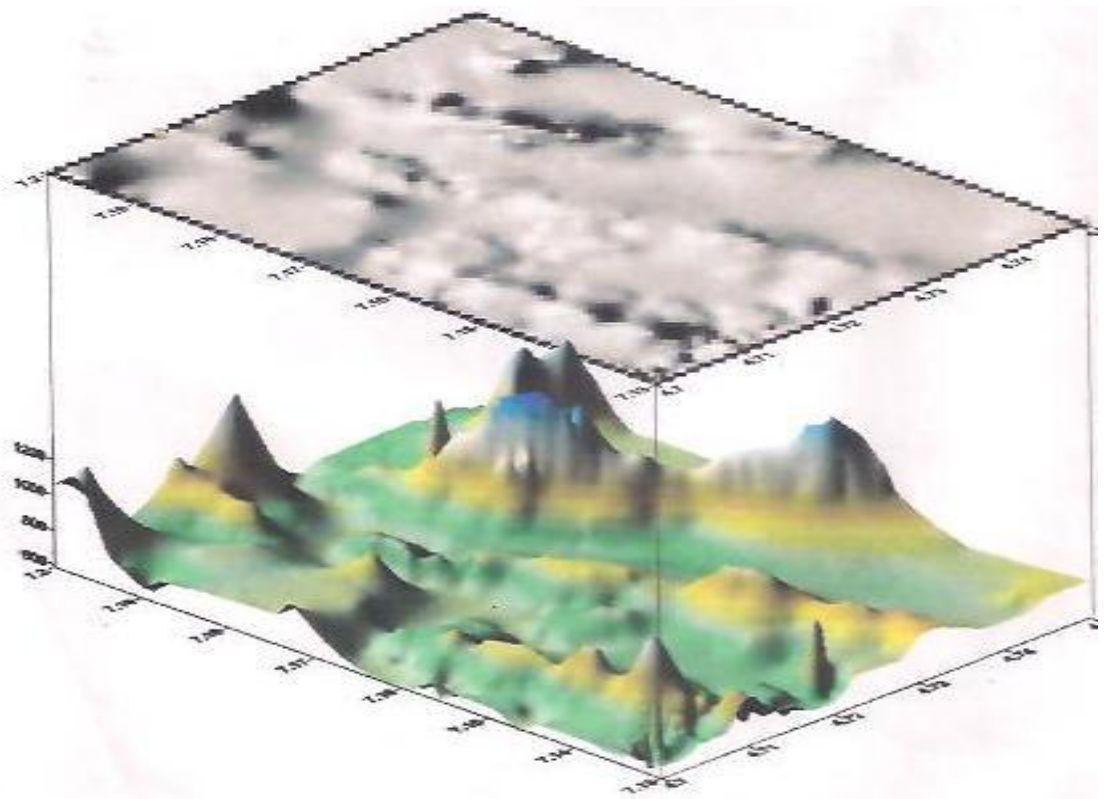

Fig 5. Geomorphological nature of Oke-Igbo .

\section{Results and Discussion}

Fig.5 of the digital modeling shows that the terrain of the study area is made up of ridges that have been denuded and distorted by weathering and erosion agents. The landscapes show obvious evidence of erosion. Erosion is responsible for the creation of hills, valleys and other denudation features emanating from drainage directions of Rivers Oni and Olori (Fig 4 ). The hilly landscape is controlled mainly by the orientation of the linearly disposed quartzite ridges.

The topographic profile and results of the slope gradient are presented in Fig. 5 and Table 3 respectively. The values of slope gradient vary between $8 \%$ and $17 \%$. The high values obtained are probably 
due to the presence of strongly resistant massive quartzite beneath which is weak, easily erodible schistose quartzite. The topography is characterized by steep slopes. The rugged topography enhances concentration and acceleration of runoff which promotes landscape sculpturing and other erosive features.

The steep slope increases soil erosion activities by enhancing the velocity of falling water. Increased velocity of the falling water sets up strong turbulent flow at base of the slope, which enhances denudation processes. The intensity of the erosion process increases with growing tangential stress and velocity of the surface runoff which is a function of slope gradient. The slope is predominantly convex in nature. The convex slope exposes the soil materials to the effect of the sun and direct impact of rainfall. Soil materials on the exposed-slopes dries much quicker resulting in a more rapid decomposition of the organic fraction of the soil materials. The organic matter in the soil acts as cemented soil aggregation, and with its rapid decomposition, soil consistency is reduced, and water erosion is promoted whenever rainfalls

The graph describes an annual cycle of rainfall peaks and troughs. The average total rainfall for the study area is $1602.44 \mathrm{~mm}$ with an average of $88 \%$ falling between April and October. The Precipitation Periodicity Index (PPI) of the study area is $255.67 \mathrm{~mm}$ (Table.3) showing high magnitude of rainfall. The rain drop under gravity impinges on the soil particles with a kinetic energy which is high enough to dislodge the particles from their in-situ position (splash erosion). The run-off velocity, especially in channels with high slopes dislodges these particles removing and transporting them down stream. The effect of rainfall in detaching soil particles is a function of drop size, intensity, and duration and soil characteristics. As rainfalls or drops of water cuts down the land surface, weathering, slope wash and mass movement come to play. This action of detachment involves pushing out the particles or lumps over the surface of detachment. This is followed by erosion and slope failure. As time goes on, the depth of erosion becomes significantly wider in relation to its breadth resulting in the development of gully erosion in the area. The mechanical and chemical actions of rain failing on an exposed land surface dislodge loose particles of soil and rock and gradually wash them away towards the leeward sides of existing natural, gradient, in a process known as rain wash resulting in soil formation. The speed at which rain drops hit the soil surface is usually the first step in the erosion process (splash-erosion). As the rainfall increases, the flow turbulence of surface run-off also doubles and thus enhances the abrasive capacity of the materials suspended in the run-off and in the land formation process.

\section{Conclusions}

The various surveys, investigations and analyses carried out during the study of the rainfall and land formation processes of the study area reveal that topography of the study area coupled with the high rainfall intensity play the major roles in the denudation process of Oke-lgbo area of Ondo State.

This study reveals the rugged topography, undulating and hilly terrain nature of the Oke-Igbo area which is as a result of the exogenetic processes of weathering, erosion, and mass wasting occasioned by heavy rainfall in the area. (Odeyemi, 1990) reports that the area is known for very long and heavy rainy seasons with an average of $33 \mathrm{~mm} / \mathrm{h}$ rainfall intensity. The steep slopes with high gradients $(8 \%-18 \%)$, gave rise to high velocity of the run-off water whenever it rains. The massive quartzite that occurs mainly at the top of ridges, and covering the weak and easily erodable schistose quartzite has resulted in the formation of steep slope. The sparseness of the vegetation cover on the landscape due to anthropogenic activities of farming and building constructions has exposed the area to erosion problems and direct impingement by rain drops .

\section{Reference}

[1]. Adefolalu D.O (1983a): Rainfall patterns in the coastal areas of Nigeria. Nigeria Geog. J., Vol. 27 (In Press).

[2]. Adefolalu D.O (1986): Rainfall trends in Nigeria. Theor. Appl. Climatol. Pg 37, 200-219

[3]. Hassan S.M., (1996). Precipitation periodicity over Kaduna State. Unpublished Masters Thesis. FUT. Minna.

[4]. Hassan, S. M and Adefolalu, D.O (2003). Precipitation periodicity and Agricultural Land use Demarcation in Kaduna State, Zuma Journal of pure and Applied Sciences, Vol. 5(2) Pp. 29-35.

[5]. Hassan,S.M., (2008). Climate variability and Crop Yield Sustainability in Federal Capital Territory, Abuja. Unpublished Ph.D Thesis. University of Abuja, Nigeria

[6]. Jegede, G. ( 1999): The effect of Groundwater and Soil properties on High pavement failure at Ayewa Locality the Journal of Techno science Vol.3, pp. $41-43$

[7]. Jegede, G. and Oguntuase, A. M; (2000): Investigation of erosion induced pavement failures along the F209 Highway at Ita-ogbolu Southwestern Nigeria, FUTA JEET, Vol. 2, pp. 30-34

[8]. Obasi, R. A and Ikubuwaje C.O. (2011). Analytical Study of Rainfall and Temperature Trend in Catchment States and Stations of the Benin- Owena River Basin, Nigeria. Journal of Environment and Earth Science ISSN 2224- 3216 (paper) Vol 2, No.3 Pp 8-20.

[9]. Odeyemi I.B. (1990) AAP and Partner Engineering Technical report on erosion activities inke-Igbo environment summated to BeninOwena River Basin Authority in 1990. 52pp

[10]. Rahaman, A.A. and Malomo, S.(1983): Sedimentary and crystalline rocks of Nigeria. Precambrian Geology of Nigeria. Geological Survey of Nigeria. Pp. $11-44$ 